\title{
Resource modeling moves into the courtroom
}

\author{
Gordon Swartzman \\ Applied Physics Laboratory 355640, University of Washington, Seattle, WA 98105, USA
}

\begin{abstract}
In this paper I discuss the use of a population dynamics model to predict the future population size of colonial seabirds after damages from a loss due to oiling. Although simple, the model was developed in a litigation context by a retained 'team of experts' and presented some challenges both in communication of results and concept to environmental lawyers and in the interpretation of results in terms of the legal issues at hand. Use of models like these involve an adversarial relationship between scientists and modelers on each side of the case. Success in these cases arises not so much from scientific credibility or credentials of the scientists as from their ability to interpret their idiom in both intuitive and common sense fashion. Given the litiginous nature of environmental issues in our country and abroad, we are likely to be more involved in such issues in the future. I conclude with suggestions on how we might effectively approach problem resolution in this context.
\end{abstract}

Keywords: Law; Murres; Pollution, water; Population dynamics

\section{Introduction}

While resource modelers may operate primarily within the scientific arena, ecological models may end up, either by intention or inadvertently, being used within a legal or political context. Involvement of scientists in the legal and political interpretation of model results can be traumatic. What may appear to be unimportant to scientists may be important in a legal context. I argue in this paper that we, as scientists and resource modelers, need to become educated and involved in this arena. By participating in this process we can (1) maintain and enhance the place of science in environmental decision making, (2) examine our own jargon-rich parlance and underlying model assumptions in light of interpretation by the law, (3) help to educate environmental lawyers about the approach, rationale and currency of the models we use and (4) play a role in establishing precedent for environmental court proceedings - our contribution to environmental advocacy if you will.

I do not mean to imply that participation in political forums and court proceedings is fun. The deposition, a process of having your work examined closely by opposition lawyers through a sworn testimony interview, is uncomfortable. Although good science is imperative in lawsuits, the development of models in service of a lawsuit differs from doing it for scientific purposes. The work is under close scrutiny by lawyers and opposing scientists. Even preliminary work may be requested for perusal. The work must frequently be performed under severe time limitations and with a team of scientists at different institutions. We have less choice in our collaborators than usual. However, to use our expertise to further public awareness of and information about environmental issues and to play a role in future environmental policy, we owe it to ourselves 
to find out more about and play a role in the arenas that affect these factors; the courts, the political arena and the news media.

In this paper I focus primarily on the use of ecological models in preparation for the courtroom within the United States legal system. In the USA, environmental cases involving interstate activities are tried in a federal court in front of a judge, who is solely responsible for deciding on the case. Through the example of the development and analysis of a bird population dynamics model, its communication to the legal world (lawyers and their minions), and the examination of this evidence by lawyers (termed deposition), I intend to share some lessons I learned in moving from a scientific model to courtroom evidence.

\section{Getting started - the approach}

My entree to the world of scientific experts began in 1991, when I was approached by the chief counsel for the U.S. Department of Justice Natural Resources Division in the case of U.S. Government and the State of California v. Apex Oil Company to help develop a model for the effect of oiling of common murres (Uria aalge) resulting from an oil spill by the

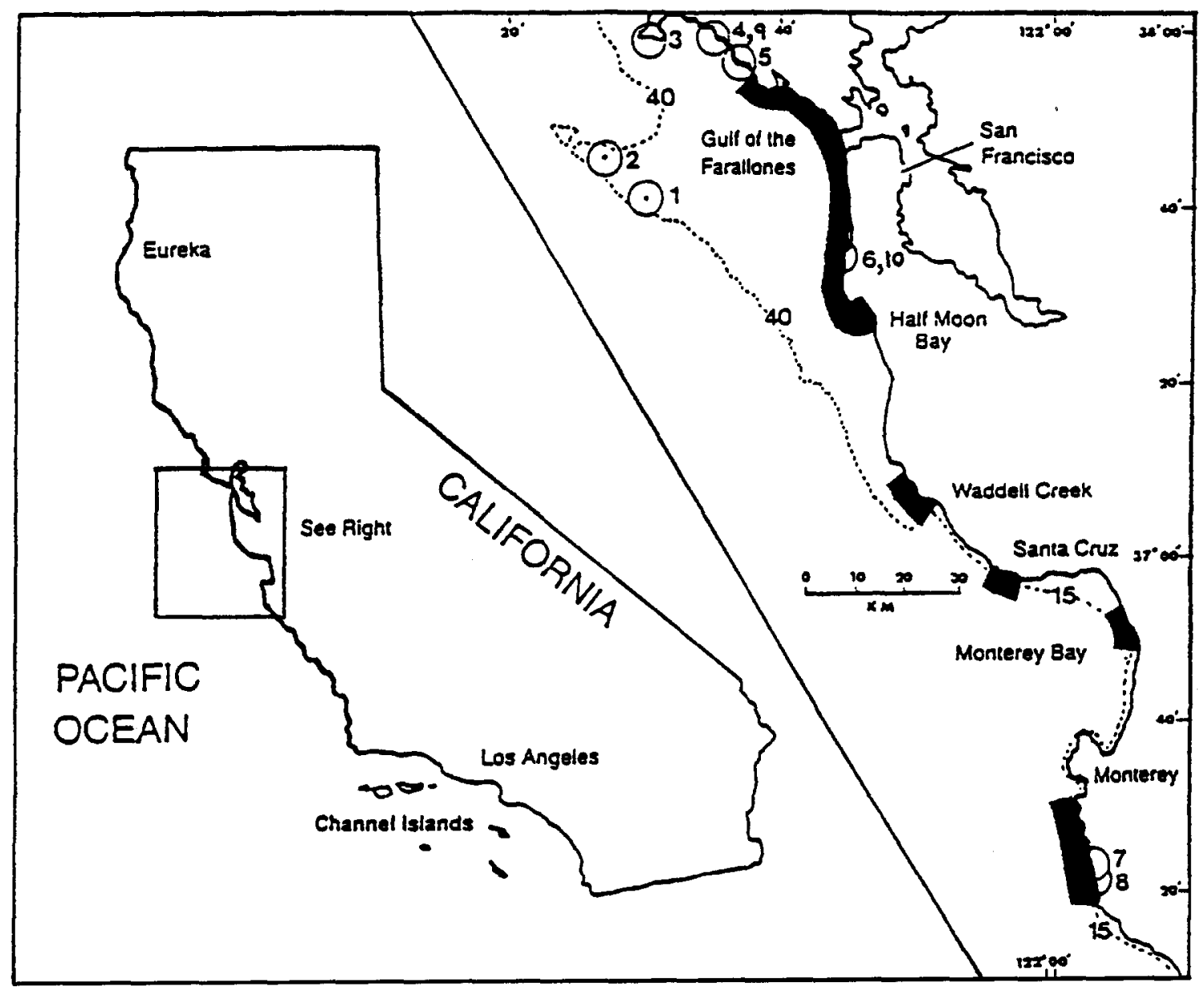

Fig. 1. Map of Central California with shaded regions delineating areas where the highest densities of oiled murres were washed ashore. The 15 and 40 fathom isobaths are shown by dashed lines. 
oil barge Apex Houston along the central California coast. The first lesson came early:

When you agree to serve as an expert for legal proceedings you are required to sign a Confidentiality Agreement. You may not share details of your work with the other side or with anyone not working for the same folks as you without permission of the Department of Justice. Importantly, this agreement in no way requires you to sacrifice the scientific integrity of your work, though it does control the audience for your work (at least while the case continues).

In my case a team of biologists had already been assembled who were knowledgeable about murres, oil effects, bird rehabilitation, statistics etc. After arriving at my first team meeting I learned my second lesson:

From their past experience lawyers want to have not only competent scientists on their team but also scientists experienced with the courtroom. They therefore are sensitive to how the scientists project. People who do not project well (either do not communicate clearly or do not project self assurance) are delegated to the background. Ultimate responsibility for the work rests with the 'testifying' expert.

The team in this case consisted of California biologists who had observed the murres after the oil spill, helped in the rescue operations on beached oiled birds, and were privy to most of the relevant data on murre biology needed to produce a model. Many of these scientists were conducting extensive monitoring of the murre colonies on the Farallon Islands (Fig. 1). Of course, this team was part of a larger group including scientists in other disciplines (e.g. economics) related to other facets of the case.

Because common murres are distributed throughout the northern hemisphere (the Central California population is at the southern end of its range), and because of the extensive study of the Farallon Island population (the major colony for Southern California common murres), there were sufficient data to produce an age-structured model of the population. Many of the parameters for this model could be estimated from studies on murres on the Farralons. In the absence of such data some parameters were estimated using studies on murre populations outside the range of interest. One parameter was extrapolated from data on gulls (also a colonial breeder but not closely related to murres). The initial model, a Leslie matrix, was developed in time for a second team meeting. Here is where I learned lesson number 3.

A model commonly accepted by scientists may contain elements that do not make common sense.

When I presented the Leslie matrix results under an increasing population scenario over a 50-year period (Fig. 2) the team statistician, a seasoned veteran, noted that the fact that this population would eventually go to infinity could make it vulnerable in the courtroom. A judge would know that the world cannot be paved with murres and might be tempted to discount the rest of my testimony. Although the current murre population showed no evidence of density-dependence in its growth within the past 20 years, we decided, after that comment, to include a density-dependent fecundity term. We postulated reduced fecundity when the population went above a threshold, due to possible overcrowding on breeding sites. The parameters in this function were calibrated to an equilibrium level above which the population could not go. This population level, though only a model construct, became associated with the ecological concept of carrying capacity. Lesson number 4 arose from this connection.

If possible avoid jargon in describing your models. The use of the term carrying capacity to

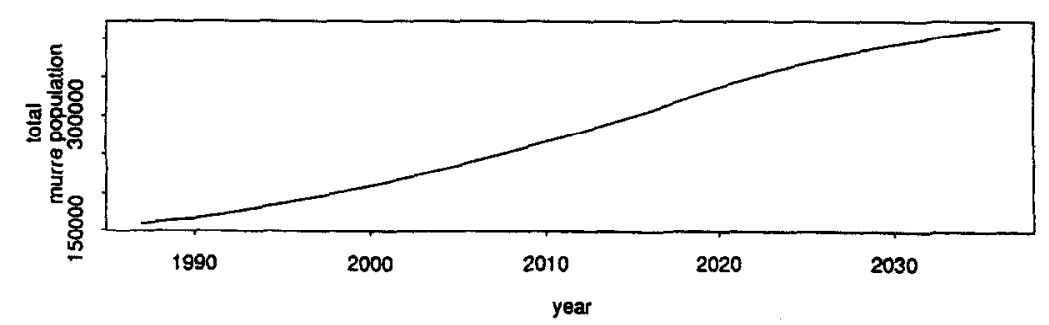

Fig. 2. Simulated total central California unoiled murre population (1986-2036) under the increasing population scenario. 
describe a density-dependent model population level led to future difficulties in arguments between the scientists on both sides of the case about what the carrying capacity of a currently declining population is.

A brief description of the model used and analysis done is given below.

\section{Brief model description}

A Leslie matrix (Leslie, 1945) model was chosen because it made best use of the population survival and fecundity data for the Central California common murre population (Swartzman and Carter, 1992). Also, the Leslie matrix is commonly used in bird population modeling (McDonald and Caswell, 1993) and has been used for modeling murres (Murphy et al., 1990). A further benefit of the Leslie matrix is its simplicity and the case of relating the model to available data. This was a wise choice as indicated in lesson number 5 .

Keep the model simple. Because in most cases you are not choosing either the species, the site or the problem to study, it is arguably better to not stretch available data to a more sophisticated alternative. Also, it is significantly easier to communicate a simple model than a complicated one. If the lawyers and the judge cannot understand the gist of the model, they are likely to discount it.

\section{Table 1}

Best estimates for central California murre population parameters and their estimated standard deviations. Literature references and explanations are provided in footnotes

\begin{tabular}{lll}
\hline Parameter & \multicolumn{2}{l}{$\begin{array}{l}\text { Estimated } \\
\text { mean }\end{array}$} \\
\hline Age 1-2 survival & $0.8^{\mathrm{a}}$ & 0.03 \\
Age 2-3 survival & $0.86^{\mathrm{a}}$ & 0.03 \\
Adult survival & $0.92^{\mathrm{b}}$ & 0.02 \\
Age 4 proportion mature & $0.3^{\mathrm{c}}$ & 0.1 \\
Age 5 proportion mature & $0.7^{\mathrm{d}}$ & 0.1 \\
Juvenile at sea survival & $0.467^{\mathrm{e}}$ & 0.148 \\
Age 4 fledging success & $0.7^{\mathrm{f}}$ & 0.05 \\
Age 5 fledging success & $0.8^{\mathrm{f}}$ & 0.05 \\
Age 6 fledging success & $0.9^{\mathrm{f}}$ & 0.03 \\
Mature female fledging success & $0.825^{\mathrm{g}}$ & 0.063 \\
Density-dependence threshold & $327000^{\mathrm{h}}$ & - \\
Zero fecundity threshold & $735000^{\mathrm{i}}$ & $(567000-903000)^{\mathrm{j}}$ \\
\hline
\end{tabular}

Notes to Table 1:

a The reduced survival of juvenile birds relative to adult survival is based on studies on gulls in the Farallon Islands (Spear et al., 1987). These studies also provide evidence that juvenile survival increases with age. We increased juvenile survival linearly with age between ages 2 and 4 . The overall survival of murres to breeding age is an average of estimates of survival to breeding age for several murre populations given by Hudson (1985) and Birkhead and Hudson (1977). The standard deviation for these values $(0.02)$ is increased to 0.03 to reflect increased uncertainty in the use of gull data.

b This value is the average of Point Reyes Bird Observatory unpublished survival estimates from 1986-1989 survival of banded adult birds. The standard deviation is also from this study.

${ }^{c}$ We used results from a study on Skomer Island (Wales) murres reported on by Hudson (1985) where $33 \%$ of birds banded as chicks first bred at age 4 . The large standard deviation reflects the small sample size of this study.

d This value is half way between the $33 \%$ value at age 4 and full recruitment at age 6 reported in Hudson (1985) for Skomer Island murres.

e That survival of young murres at sea is highly variable is demonstrated by a study on beached Oregon murres by Bayer ct al. (1991). The survival estimate is based on survival of banded birds to adulthood on the Helgoland Island (Mead, 1974) and Skomer Island (Birkhead and Hudson, 1977) murre populations along with juvenile survival estimates given above.

Fledging success estimates are based on evidence from gulls on the Farallon Islands suggesting that breeding success increases with parent age and experience (Pyle et al., 1991; Sydeman et al., 1991). We assumed that fledging success increases linearly between ages 4 and 7 .

$\mathrm{g}$ Mature female fledging success is based on studies of fledging and egg laying success conducted from 1972-1986 on the Farallon Islands and reported on in Appendices 3.1 and 8.1 in Ainley and Boekelheide (1990).

${ }^{\mathrm{h}}$ This is the population level above which density dependence begins (fecundity is reduced with increasing density). A conservative estimate equal to the estimated central California population level in 1982 (which showed no evidence of density-related reduced fecundity) was used.

${ }^{\mathrm{i}}$ This value was calibrated to give a murre population carrying capacity of 567000 , extrapolated from an estimate of the highestever observed Farallon I. population, reported in Ainley and Lewis (1974). This value is conservative since, as discussed in their section 2.2, footnote 5 , the total central California murre population at its maximum may have been significantly larger than 567000 .

${ }^{\mathrm{j}}$ The range of values shown is given instead of a standard deviation because there is considerable uncertainty about how much of the central California population consisted of Farallon Island birds at the time of their reported highest-ever population level. This uncertainty resulted in our use of a uniform instead of a normal distribution for this parameter in the sensitivity analysis. 
The Leslie matrix model can be represented by $n(t+1)=\Lambda n(t)$, where $n(t)$ is a vector of the female population at time $t$ and $\Lambda$ is the time-independent survival-fecundity matrix, having age-specific fecundities in the first row (female offspring surviving to age 1 per age $i$ female in column $i$ ) and survivals from age $i+1$ along the sub-diagonal.

The modeling work was conducted in three phases: a calibration or data fitting phase, a prediction phase and a sensitivity analysis phase. Prior to the calibration phase, model parameter estimates were oblained for murre populations from the literature and from other unpublished studies on the central California murre population. Because the population continued to decline after the 1986 oil spill we considered two alternative future population scenarios: (1) a continued population decline scenario and (2) a population increase scenario.

The increase scenario provided optimistic predictions of the future of the murrc population. Both scenarios were based on the same model with slightly different parameter values. Age-specific survival rates were slightly lower in the continued decline scenario, being chosen to fit the observed population decline between 1986 and 1989.

A density-dependence term was added to fecundity that progressively reduced each of the fecundity values at higher population sizes (i.e. if the total central California murre population was between 327000 and the zero fecundity threshold). The zero fecundity threshold is interpreted as that population level at which murre breeding success (fecundity) effectively drops to 0 . The zero fecundity threshold was larger than the maximum attainable population size, which was the point at which fecundity exactly balanced mortality.

When the population drops to low levels, social factors may prevent breeding, although individuals are capable of reproduction. We did not include this second type of density-dependence in our model. Translation from female to total population was made assuming a $1: 1$ sex ratio (there is no evidence for an unequal sex ratio for murres).

The fecundity terms were the product of agespecific maturity (the fraction of females in each age class that breed), the sex ratio (the fraction of each age class comprised of females; assumed $50 \%$ ), the age-specific fledging success (the number of young birds produced by birds of age $i$ that survive to leave the breeding colony) and the survival of young-ofthe-year (birds less than one year old) at sea after fledging.

Before running the simulation we conducted a literature and available unpublished data review to provide 'best estimate' values and their standard deviations (s.d.) for murre population parameters. These parameters included age-specific survival, maturity, breeding (fledging) success and carrying capacily (fecundity thresholds). All parameters except for survival were the same in both scenarios. The best estimate parameters and their estimated variance are listed in Table 1. The survival parameters for the population increase scenario were $3 \%$ higher than those for the continued decline scenario, while the best estimate parameter values were intermediate between these two cases.

\section{Model calibration}

The age distribution of the murre population in 1982 , the starting year for the simulation, was obtained by running the model from 1970 until 1982 using parameters fit to the observed population increase over that period. The model was then run, using either the decline or increase scenarios, for a 55-year period after 1982. Included in the post-1982 simulations are gillnet, oil spill and El Niño losses of murres reported from 1982-89 (e.g. Takekawa et al., 1990) and reductions in fecundity in 1982-84 due to El Niño (Ainley and Boekelheide, 1990; Point Reyes Bird Observatory, unpublished data). These latter reductions were based on observation of laying and fledging success on the South Farallon Islands during these years and on estimates of at-sea mortality during the first year of life (Point Reyes Bird Observatory staff, pers. commun.). To simulate the Apex Houston 1986 oiling, 3164 females (or 6327 total birds), the number of females estimated killed from the oil spill, were removed from the population in proportion to their simulated age distribution (assuming no age bias in susceptibility to oiling mortality). This estimate was based on numbers of oiled murres found dead on beaches just after the spill, estimated numbers of oiled murres lost at sea and estimated numbers of oiled murres recovered alive on beaches, 


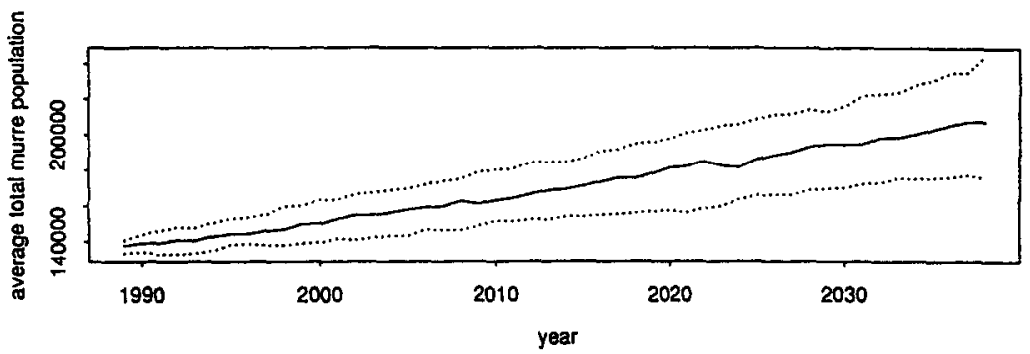

Fig. 3. Simulated 50-year oiled murre population for parameter values given in Table 1 . The solid line shows the median population and the dashed lines the upper and lower quartiles for 100 Monte Carlo simulations.

brought to rehabilitation centers and lost either at the centers or after release (Siskin et al., 1993).

Two hundred 50-year simulations were made of the murre population after 1982 . These simulations were used to determine variability in the murre population predictions. Monte Carlo samples were taken from the survival, fecundity and zero fecundity threshold parameters annually for each of the 200 simulations. In this way, a range of predicted outputs were produced, providing a measure of variance for the future population projections. To implement this technique, we estimated the variance in survival and fecundity parameters based on data from murres and other species at the Farallon Islands and literature (see Table 1). The 'best estimate' parameters used in this sensitivity study are intermediate between the continued decline and population increase scenario estimates. The median 50-year population simulation and difference between unoiled and oiled murre populations are shown in Fig. 3 and Fig. 4, along with the upper and lower quartiles for 50 years from the 200 simulations.

\section{Results communication}

The document describing the model (Swartzman and Carter, 1992) was much different from the above description. Leslie matrices, density dependence, Monte Carlo and even population projection are not familiar to many in the legal profession. As such, all jargon was explained in lay terms. Measures of model performance were presented in several ways so as to nail home the messages from the model. In this case they were:

1. The impact of a loss of part of a population plays out over time, with the loss depending on the potential progeny of birds lost as well as on the current loss. This was depicted by the birdogram in Fig. 5.

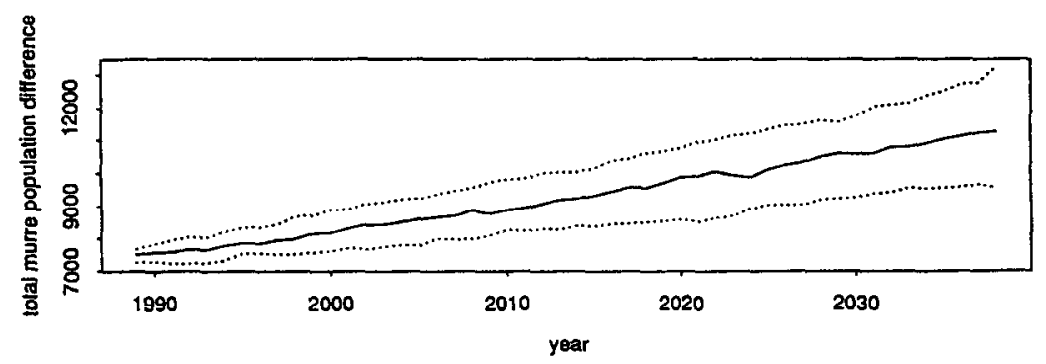

Fig. 4. Median difference (solid line) hetween the unoiled and oiled Monte Carlo simulated murre populations. The upper and lower quartiles of this difference are shown with dashed lines. 


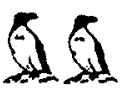

year $0 \quad 2.0$

ass

year 102.87

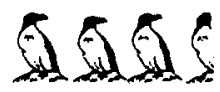

year 203.64
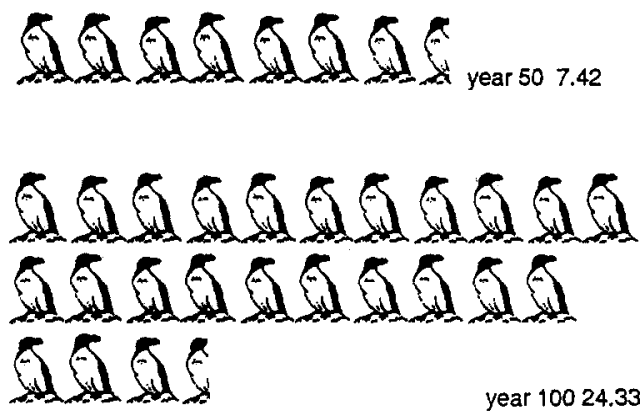

Fig. 5. A histogram showing the number of progeny resulting at different future times from a single pair of murres according to the population increase scenario. Histogram numbers are illustrated with iconified murres.

2. Model parameters are not known with complete certainty and in projection of a population into the future the implications of this uncertainty or variability must be considered. This was represented through quartiles as in Fig. 3 and Fig. 4.

Lesson number 6

Part of the challenge of moving models into the courtroom is the communications challenge. While a scientist may be impressed by a technical, and concise explication, educated laypersons may not be able to understand a highly technical presentation. Because the judge must decide on the merits of the case, whatever merits your case has need to be clear to the judge. I recommend doing a good job on the science, but put on your plain language hat to describe it in simple terms.

Lesson number 7

Provide enough information (either in tables, appendices or computer code) for someone else to repeat what you have done, but do not burden your report(s) with lengthy explanations. In general, the more you say the more vulnerable you will be to appearing contradictory.

\section{Lesson number 8}

Be creative in how you communicate and present your results. Create the maximum impact with them. Think of common sense arguments to support or communicate a result. Use of analogy is often effective. While the birdogram we used (Fig. 5) may appear silly, it was effective.

\section{Who are the players}

While the case I was involved in was prosecuted by the U.S. Department of Justice (i.e., they were conducting the lawsuit) other government agencies were involved as clients; defined by the laws to be their upholders. In this case the clients (of the Department of Justice) were the U.S. Fish and Wildlife Service, the National Oceanographic and Atmospheric Administration (NOAA) and the State of California. The clients had lawyers on their staff who came to meetings, though they were not prosecuting the case. There were also biologists on our team who were part of client agencies. These persons offered information as requested and were involved in conducting and facilitating peer review of the scientific products of team experts. This modus operandi, with client peer reviews, lawyers and biologists is quite different from most work in science, where the roles of the participants are defined on the basis of their expertise. They seemed to be better aware of the big picture than I was and were informative about the case strategy.

\section{The deposition}

A major hurdle in any legal proceedings where you are an expert is the deposition. I always thought of deposition as something that only happened to kings or dictators, but under the U.S. law experts can also be deposed. The use of this term is apt, because deposition of witnesses is a pre-trial examination of you, your activities on the case and documents you have been asked to produce deemed relevant to the case by opposing lawyers. It is the job of lawyers to show opposing witnesses in their worst light and, while deposition often appears to evolve as an attempt to clarify what you have said and done it is 
also a chance to get you to say something damaging to your case.

Before the deposition you will be requested to turn over to the opposition counsel a large amount of relevant material. They may request all versions of your expert report, all versions of the model, all notes, all papers recently reviewed relevant to the case, all proposals you have written on relevant topics. Clearly this can make for a prodigious amount of material, much of which may not appear relevant to you. To me this process seemed wasteful of both paper and time. Personnel must be retained to read all this material and judge its relevance.

While all depositions are different I will briefly review my deposition as an example. Questions proceeded as follows (though the order wasn't pre-defined and a previous topic could be returned to at any time):

- Review of Curriculum Vitae and relevant articles.

- Review of all drafts of the model report (in this case there were nine), from the earliest to the latest, with detailed discussion of and justification for differences.

- Review of all relevant meetings and conversations I participated in.

- Review of all versions of the model source code presented with discussion of and justification for differences.

- Review of all interactions and correspondence with other personnel involved in the case.

- Requests for my opinion about many biological questions which I am not an expert on.
Throughout the deposition there were many requests to define terms used in the paper, including modeling and biological terms. For example, I provided definitions for stochastic and deterministic models, continuous and discrete models, density dependence, Leslie matrix, survival and fecundity, depensatory and compensatory mortality, Monte Carlo experiments, sensitivity analysis, time horizon, subadult bird, and carrying capacity.

Lesson number 9

No matter what you do the deposition will be painful because it is by nature adversarial. Make sure you are prepared by your lawyers. Some take home messages for me were:

Make sure to check documents for details before answering.

Take as much time to answer as you want.

If questions are vague to you have them clarified. Answer the question asked and no more.

Take breaks when needed.

The focus of the depositions (both my own and that of the modeler on the other side) was on detailed examination of our reports. The reports highlighted some major differences in how oil-spill damage should be interpreted.

My approach was to consider the damages from the oil spill in terms of the difference, over a finite time interval (i.e., 50 years) in model predictions between the oiled and unoiled (the population behaving as if the oiling did not happen) populations. I defined this difference in a variety of ways. including the difference in numbers of birds 30 and 50

Table 2

Oiled and unoiled simulated murre populations compared through a number of measures of impact. Ranges of values for the comparison measures are given in parentheses. Estimated comparison after 30 and 50 years from sensitivity analysis between simulated oiled and unoiled populations

\begin{tabular}{lccl}
\hline Factor & Mean & Std. dev. & Range \\
\hline Diff. after 30 years & 9650 & 1618 & $(5866-14350)$ \\
Diff. after 50 years & 11400 & 2342 & $(6166-17650)$ \\
30-year bird-year diff. & 255183 & 26852 & $(183278-347818)$ \\
50-year bird-year diff. & 465152 & 59269 & $(302245-630547)$ \\
Years to recover to original loss level & $50+$ & $4.5^{\mathrm{a}}$ & $(5-50+)$ \\
\hline
\end{tabular}

a This distribution is highly skewed. Less than $5 \%$ of the simulations result in the difference ever returning to the original loss level within 50 years. 
years after the oil spill, the time-integrated difference in birds between the two scenarios over 30 and 50 years. I termed the integrated difference the bird-year difference. It is the sum of the differences in birds between the two scenarios for the time period of interest. I also used the number of years the oiled population would take to recover to within 6327 birds (the estimated number of birds lost due to the oil-spill) of the unoiled case as a measure of the oiling impact (Table 2).

The modeling expert on the other side chose alternative ways of assessing damage. While admitting that the density-dependent fecundity term makes my model different from a Leslie matrix model, he first calculated the rate $r$, the exponential rate of increase (or decrease) resulting from a survivalfecundity matrix with parameters as reported in Table 1. The parameter $r$ can be calculated from a survival-fecundity matrix by solving the polynomial equation, resulting from setting the determinant of $\Lambda-\lambda I$ equal to 0 , for the unknown $\lambda$. The rate of increase or decrease $r$ is the natural logarithm of the largest $\lambda$ (called the dominant eigenvalue of matrix $\Lambda$ ), which, for the Leslie model, is always unique and has a value greater than 0 . Over a long time horizon the population, modeled using a Leslie matrix model, increases or decreases exponentially at rate $r$. A population loss (such as occurred through bird oiling) is seen as introducing a time lag between two exponentially changing populations. The time lag is the number of years it would take the lagging population to reach the population level of the leading population assuming they have both reached the condition of exponential growth or decline. This time lag equals $1 / r$ times the natural logarithm of the ratio of the unoiled to oiled population at the time of the spill (the ratio of the initial conditions of the two populations). For our increasing and declining scenarios these time lags were 1.8726 and -1.0928 years respectively. In the declining scenario $r<0$; therefore the oiled population is leading the unoiled population in decline and the time lag is the number of years in the past at which it was at the level of the current unoiled population, which accounts for why the time lag is a negative number.

The opposing modeling team suggested that our bird-year measure was misleading in that it did not normalize the bird-year difference to the actual popu- lation levels. When this was done they found that the bird-year difference was never more than $4 \%$ of the total bird-years experienced by the population. This dichotomy is analogous to the half full, half empty interpretation of a glass with $50 \%$ of its potential contents. Counting bird-year differences and time to recoup losses focuses on the losses and produces large numbers (Table 2). Looking at time lags of exponentially growing and declining populations over long time horizons and on normalized bird-years focuses on the total population and produces small numbers, because the original loss was a small fraction of the total population.

This difference in model interpretation, without differences in model approach, pervaded other aspects of the model. We emphasized a 50-year planning or effects time horizon, where the impact of the loss still lingered in the memory of the population (so to speak). They employed a long-term (infinite) time horizon, looking at exponential growth or decline of the population when the difference between the oiled and unoiled population depends only on a (small) time lag. Our analysis also included a time lag; the time from the start of the simulation needed to make up the difference between the oiled and unoiled population lost in the spill. Because of the finite time horizon the effects of the loss are recent in our analysis and resulted in a much larger lag period than in the infinite time horizon analysis.

Both sides agreed that there were insufficient data to make a stochastic version of the population model. However we both looked at parameter variability in interpreting results. We used Monte Carlo simulation to generate annual changes in survival and fecundity parameters reflecting our uncertainty about these parameter values. This generated a set of 200 realizations of the model, which was used to provide estimated median simulation values and error bars (Fig. 3 and Fig. 4) to generate the range of plausible behaviors of the model. They, alternatively, looked at a stochastic population model to estimate the difference in eventual extinction probability and time to extinction. For a Leslie matrix model where the survival-fecundity matrix is generated from an environmental stochastic process, Tuljapurkar (1990) showed that the total population size is eventually $\log$-normally distributed with a mean that grows at a rate $r$ ( $r$ defined as above) and a variance that grows 
at a rate $\sigma^{2}$. They were able to compute the extinction probability and time to extinction for this model. However, since there was insufficient information to estimate $\sigma^{2}$, they looked at the change in extinction probability and time to extinction between the oiled and unoiled populations over a wide range of alternative values of $\sigma^{2}$. They then showed that, over the range of values tried, the oil spill produces no more than an $8 \%$ increase in the probability of extinction (defined as a $99 \%$ population decline). This exercise is only relevant for the increasing population scenario, because for the declining scenario the probability of extinction is always 1 (independent of the initial population size).

Here we see again the difference in focus. I looked at estimated parameter variability as providing a range of plausible model behaviors over a relatively short time horizon. They looked at variability as providing estimates for extinction probabilities over an infinitc time horizon, without considering the actual estimates of parameter variability but only a wide range of variability. I used parameter variability to demonstrate robustness of model predictions to a plausible range of parameter values. They used parameter variability in a theoretical way to estimate extinction probability in a stochastic Leslie matrix model. They were less concerned with the plausible or probable behaviors of the model than they were with the possible behaviors. In my opinion, the difference in focus between plausible and probable outcomes versus possible outcomes best characterizes the difference between our approaches.

It is difficult to be objective regarding interpretation of model results, and of course I think my approach was more appropriate than that used by the opposing side. Clearly, the further off in timc the effects of the oil spill are carried the less significant they become. Therefore, it is not surprising that I focussed on a finite time horizon and the opposing side on an infinite horizon. It is also clear that a wider range of possible behaviors exist than probable behaviors and that scanning a set of possible behaviors of a model will result in a more equivocal result than when only probable or plausible outcomes are considered. Again, not surprisingly, the opposing side, who wanted to minimize the effect of the oil spill, devised a means to consider a wide range of possible outcomes without regard to plausibility.

\section{The big picture}

Despite the difficulties in developing, interpreting and defending natural resource models in the legal arena I believe I gained significantly by so participating.

First, I got a first hand interpretation of the law regarding my issue of concern. While we often see the law as vague and arbitrary, it in fact is usually a good faith effort at defining the environmental problem and how to deal with it. For example, I believe oil spills are bad and that perpetrators of oil spills ought to take responsibility for their actions, especially if the spill resulted from negligence. The U.S. laws in this regard are the National Environmental Policy Act and the Clean Water Act. They specify which government agencies are the guardians of the environment and outline the means by which the polluters will be required to reimburse society for damages.

Second, as a modeler I got to play a role in helping to devise an effective strategy for a case. Frequently environmental effect cases like the one I was involved in revolve around the likely short- and long-term effects on the population (system) and relate to the risk of further decline resulting from the insult of concern. Long term and risk conceptually imply prediction, and results need to be interpreted in light of uncertainty in the models, parameters and future behavior of the system. My challenge was to bring these ideas across in a fashion that did not jeopardize recognition of the fact that the model and parameter estimates are based on the best available data. Quantitative predictions of the model need to be presented in risk or probability terms. Scenarios can be used to show the implications of alternative futures on performance of the biota of concern (Table 2).

Third, I was able to educate the lawyers about resource modeling. In educating lawyers and the legal profession about risk, I introduced probability directly into the interpretation of model output. I believe that a context must be developed to allow the law to distinguish between possible, plausible and probable outcomes. We can display all possible outcomes (probably not useful), choose scenarios that are plausible and interpret outcomes as to their probability. Under current U.S. law plausibility plays a 
large role. Plausibility is taken to mean: "Is it more probable than not?'" We need to choose whether we want to accept this mind set or whether we can provide more precise answers in the realm of probability.

Part of the education of lawyers was to build their trust in me as an expert. I had one lawyer add up a set of percentages that were calculated to 2 decimal places but written out to 1 decimal place and come up with $100.1 \%$ and told me that the numbers must be wrong. I understood that this was, in part, his focus on a minuscule part of the modeling picture to bolster his inadequate comprehension of how the model worked. When you can help the lawyers to get the big modeling picture and follow the steps that lead to the conclusions, then they do not need to pick on the little things.

\section{What we can do}

As the world society comes to grip with the impacts of our collective actions on the environment, fingers are being pointed. However, our commitment and rights to protect our environment and pursue environmental wrongdoers is actualized through our laws. Therefore, we must work at understanding the laws. By doing so, we can learn the merits of each case and what our client is trying to achieve. We can educate lawyers about the assumptions and approach used for the modeling and the way our models deal with uncertainty and environmental variability.

Through our involvement we can learn not only about the law but also about alternative ways to assess and pay for damages (education, recolonization, research). We can work closely with our professional societies to develop standards for how our work is to be used. We must be prepared to put up with the quirks of this system and its practitioners. We must take special care to communicate results in plain English without the jargon (or with the jargon demystefied).

While the scientists and lawyers involved in a case may be looking to models for predictions, we must emphasize that modeling is, above all, an integrative tool. It can serve to coalesce a team around scientific issues, influence what data must be col- lected or amassed, indicate the implications of a particular set of model hypotheses, and help learn more about the study system and their biota. The results of various environmental depredations will play out in a future about which we are uncertain. This can be best considered in model predictions through including probabilities for various outcomes and through investigating the implications of alternative scenarios (like the increasing and decreasing population scenarios in the murre model). Rather than being brought in to patch together existing data into a prediction, we modelers should work as part of a team of lawyers and biologists to focus the scientific work toward the legal questions at hand.

\section{Acknowledgements}

I would like to acknowledge the many scientists and lawyers who helped educate me into the ways of science in the courtroom. These include Valerie Lee, Jim Nicoll, Harry Carter, Steve Kress, Michael Fry, and Bernie Siskin. I also appreciate the comments of the reviewers, Robert McKelvey and Barry Noon, for providing suggestions that have improved the manuscript.

\section{References}

Ainley, D. and Boekelheide, R. (Editors), 1990. Seabirds of the Farallon Islands: Ecology, Dynamics and Structure of an Upwelling-system Community. Stanford Univ. Press, Stanford, CA.

Ainley, D.G. and Lewis, T.J., 1974. The history of Farallon Island marine bird population, 1874-1972. Condor, 76: 423-446.

Bayer, R.D., Lowe, R.W. and Loeffel, R.E., 1991. Persistent summer mortalities of common murres along the Oregon central coast. Condor, 93: 516-525.

Birkhead, T.R. and Hudson, P.J., 1977. Population parameters for the common guillemot Uria aalge. Ornis Scand., 8: 145-154.

Hudson, P.J., 1985. The Atlantic Alcidae. Academic Press, London.

Leslie, P.H., 1945. On the use of certain matrices in population mathematics. Biometrika, 33: 183-212.

McDonald, D.B. and Caswell, H., 1993. Matrix methods for avian demography. In: D.M. Power (Editor), Current Omithology Vol. 10. Plenum, New York, NY, pp. 139-185.

Mead, C.J., 1974. The results of ringing auks in Britain and Ireland. Bird Study, 21: 46-48.

Murphy, E.C., Springer, A.M. and Roseneau, D.G., 1990. Popula- 
tion status of common guillemots Uria aalge at a colony in western Alaska: results and simulations. Ibis, 128: 348-363.

Pyle, P., Spear, L.B., Sydeman, W.J. and Ainley, D.G., 1991. The effects of experience and age on the breeding performance of western gulls. Auk, 108: 25-33.

Siskin, B.R., Page, G.P. and Carter, H.R., 1993. Impacts of the 1986 Houston oil spill on marine birds in Central California. U.S. Dept. of Justice technical report, 17 pp. + appendices.

Spear, L.B., Penniman, T.M., Penniman, J.F., Carter, H.R. and Ainley, D.G., 1987. Survivorship and mortality factors in a population of western gulls. Stud. Avian Biol., 10: 44-56.

Swartzman, G. and Carter, H., 1992. Long-term injuries to the
Central California population of common murres (Uria aalge) due to mortality from the 1986 Apex Houston oil spill. U.S. Depth of Justice technical report, 33 pp.

Sydeman, W.J., Penniman, J.F., Penniman, T.M., Pyle, P. and Ainley, D.G., 1991. Breeding performance in the western gull: effects of parental age, timing of breeding and year in relation to food availability. J. Anim. Ecol., 60: 135-149.

Takekawa, J.E., Carter, H.R. and Harvey, T.E., 1990. Decline of the common murre in Central California, 1980-1986. Stud. Avian Biol., 14: 149-163.

Tuljapurkar, S., 1990. Population Dynamics in Variable Environments. Springer-Verlag, New York, NY. 